\section{JURNAL ABDIMAS

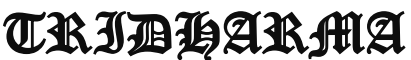

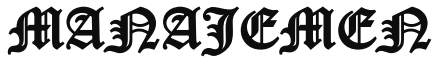

P-ISSN 2615-6849, E-ISSN 2622-3686

Jurnal ABDIMAS Vol. 1,No. 3,September 2020,Hal (42-47)

@ Prodi Manajemen Fakultas Ekonomi Universitas Pamulang

Email: abdimasjurnal.unpam@gmail.com Telp: (021) 741-2566

\title{
SOSIALISASI UNDANG-UNDANG KDRT DAN PERLINDUNGAN ANAK
}

Bambang Wiyono, Gregorius Hermawan K, Endi Arofa, Eka Martiana Wulansari, Susanto

Dosen Magister Hukum Universitas Pamulang

Emailsusanto@unpam.ac.id

\begin{abstract}
ABSTRAK
Harapan setiap keluarga adalah keharmonisan, akan tetapi tidak semua keluarga mengalami hal tersebut. Kekerasan Dalam Rumah Tangga (KDRT) selalu menjadi perbincangan hangat masyarakat Indonesia dari tahun ke tahun, terutama setelah rancangan undang-undang tentang penghapusan kekerasan dalam rumah tangga disahkan menjadi UU-RI no. 23 tahun 2004.

Tujuan kegiatan ini adalah untuk memberikan materi-materi tentang UndangUndang Perlindungan Anak dan Undang-Undang KDRT yang berlaku saat ini di dalam sistem hukum Indonesia. Permasalahan yang dihadapi oleh mitra adalah belum secara keseluruhan adalah kurangnya pemahaman dan wawasan tentang hukum dan perundangundangan dalam sistem hukum Indonesia, khususnya tentang Undang-Undang Perlindungan Anak dan UndangUndang KDRT. Solusi yang ditawarkan dalam kegiatan ini adalah agar masyarakat khususnya yang ada dilokasi kegiatan dalam hal ini para kader PKK dan petugas Posyandu di Tangerang Selatan mampu menyerap materi-materi pengetahuan dan menyampaikan kepada masyarakat dilingkungannya.
\end{abstract}

\section{Kata Kunci: Perlindungan Anak, Kekerasan Dalam Rumah Tangga}

\section{ABSTRACT}

The hope of every family is harmony, but not all families experience it. Domestic Violence (KDRT) has always been a hot topic of discussion among the Indonesian people from year to year, especially after the draft law on the elimination of domestic violence was passed into Law-RI no. 23 of 2004.

The purpose of this activity is to provide material on the Child Protection Act and the Domestic Violence Act currently in the Indonesian legal system. The problem faced by partners is not as a whole is the lack of understanding and insight about the law and legislation in the Indonesian legal system, specifically regarding the Child Protection Act and the Domestic Violence Act. The solution offered in this activity is for the community, especially those in the activity location, in this case the PKK cadres and Posyandu officers in South Tangerang to be able to absorb knowledge materials and deliver them to the community.

\section{Keywords: Child Protection, Domestic Violence}

\section{PENDAHULUAN}

Kekerasan terhadap perempuan dalam Undang-undang Nomor UU No 23 Tahun 2004 didefinisikan sebagai setiap perbuatan terhadap seseorang terutama perempuan, yang berakibat timbulnya kesengsaraan atau penderitaan secara fisik, seksual, 


\section{JURNAL ABDIMAS

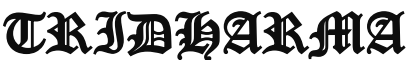

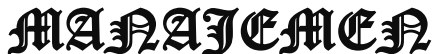

P-ISSN 2615-6849, E-ISSN 2622-3686

Jurnal ABDIMAS Vol. 1,No. 3,September 2020,Hal (42-47)

@ Prodi Manajemen Fakultas Ekonomi Universitas Pamulang

Email: abdimasjurnal.unpam@gmail.com Telp: (021) 741-2566 psikologis, dan/atau penelantaran rumah tangga termasuk ancaman untuk melakukan perbuatan, pemaksaan, atau perampasan kemerdekaan secara melawan hukum dalam lingkup rumah tangga. Mirip dengan itu, pengertian "kekerasan terhadap anak" dalam Undang-undang Nomor 35 Tahun 2014 adalah setiap perbuatan terhadap anak yang berakibat timbulnya kesengsaraan atau penderitaan secara fisik, psikis, seksual, dan/atau penelantaran, termasuk ancaman untuk melakukan perbuatan, pemaksaan, atau perampasan kemerdekaan secara melawan hukum. Meski konsekuensi hukumannya cukup berat, dan kalangan pemerintah maupun masyarakat sipil pun telah bekerja keras mengatasinya dengan menghabiskan dana serta sumber daya lainnya yang kian tahun semakin meningkat, namun kasus-kasus kekerasan terhadap perempuan dan anak di negeri ini justru bertambah gawat dan mengkhawatirkan. Sepertinya para pelaku kekerasan itu tidak takut sedikit pun dengan ancaman hukuman.

UU-PKDRT no. 23 tahun 2004, terlepas dari debat yang melingkupinya, telah menggeser wilayah persoalan privat menjadi persoalan publik. Ada harapan besar dari implementasi UU ini diantaranya terhentinya budaya kekerasan yang ada di tengah masyarakat, dimulai dari wilayah yang paling menetukan yaitu rumah. Stereotype jender yang telah melekat pada laki-laki dan perempuan, seringkali menjebak kedua jenis kelamin ini pada posisi yang sulit. Hal ini juga menandakan, mereka yang bergerak pada wilayah feminist legal theory yang berusaha merekonstruksi sistem hukum yang netral, obyektif, dan transformative, mulai menuai hasil. Netralitas hukum yang mengandaikan imparsial (tidak memihak) pada satu pihak atau golongan, sehingga dalam perkembangannya hukum berdampak pada keberadaan perempuan. Obyektivitas hukum dicapai jika polaritas dan dikotomi maskulinfeminin dihilangkan. Dengan demikian, kekerasan di wilayah domestik juga dianggap sebagai tindak kejahatan. Transformatif bermakna tidak hanya perubahan dalam traktat hukum, melainkan modifikasi mekanisme hukum yang adil bagi perempuan. Feminist legal theory memperjuangkan konsep hukum yang didasari oleh pengalaman perempuan sebagai starting point. Kesadaran hukum bagi perempuan pun perlu dibangun untuk memperoleh hak-hak dan kesempatan yang sama.

Jika ketidaksetaraan dan ketidakadilan dalam menempatkan posisi laki-laki dan perempuan adalah konstruksi masyarakat, maka kekerasanpun adalah bagian dari konstruksi itu. Masyarakat bertanggung jawab atas pembelajaran tentang bagaimana menjadi laki-laki, sehingga laki-laki mengaktualisasi kemaskulinannya melalui tampilan diri yang macho, gagah, kuat, agresif. Maka sekarang saatnya bagi masyarakat mengubah pelabelan jender ini menjadi lebih manusiawi, sehingga cara-cara mengaktualisasikan diri juga menjadi lebih assertif di masyarakat. Dengan demikian, keadilan jender sebagai suatu kondisi dan perlakuan yang adil terhadap perempuan dan laki-laki dapat terwujud. Diperlukan langkah-langkah untuk menghentikan hal-hal yang secara psikis, politik, dan sosial budaya menghambat perempuan dan laki-laki untuk bisa 


\section{JURNAL ABDIMAS

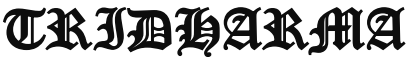

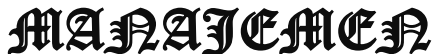

P-ISSN 2615-6849, E-ISSN 2622-3686

Jurnal ABDIMAS Vol. 1,No. 3,September 2020,Hal (42-47)

@Prodi Manajemen Fakultas Ekonomi Universitas Pamulang

Email: abdimasjurnal.unpam@gmail.com Telp: (021) 741-2566 berperan dan menikmati hasil dari perannya itu. Kesetaraan yang adil merupakan suatu konsep yang mengakui faktor-faktor khusus seseorang serta memberikan haknya sesuai dengan kondisi orang tersebut (person-regarding equality). Jadi, bukan memberikan perlakuan yang sama kepada individu yang berbeda kebutuhan dan aspirasinya, tapi memberikan perhatian yang sama kepada setiap individu agar kebutuhannya dapat terpenuhi.

\section{Rumusan Masalah}

Dengan mempertimbangkan latar belakang yang sudah diutarakan diatas kami berinisiatif untuk membentuk pengabdian kepada masyarakat yang sudah bekerjasama dengan Pemerintah Kota Tangerang Selatan untuk melakukan sosialisasi mengenai KDRT dan Perlindungan Anak.

Adapun rumusan masalah yang dangkat adalah : Bagaimana pengaturan KDRT dan Perlindungan Anak?

\section{TINJAUAN PUSTAKA}

\section{Kekerasan Dalam Rumah Tangga}

Kekerasan dalam Rumah Tangga seperti yang tertuang dalam Undang-undang No.23 Tahun 2004 tentang Penghapusan Kekerasan dalam Rumah Tangga, memiliki arti setiap perbuatan terhadap seseorang terutama perempuan, yang berakibat timbulnya kesengsaraan atau penderitaan secara fisik, seksual, psikologis, dan/atau penelantaran rumah tangga termasuk ancaman untuk melakukan perbuatan, pemaksaan, atau perampasan kemerdekaan secara melawan hukum dalam lingkup rumah tangga.

Masalah kekerasan dalam rumah tangga telah mendapatkan perlindungan hukum dalam Undang-undang Nomor 23 tahun 2004 yang antara lain menegaskan bahwa: a. Bahwa setiap warga negara berhak mendapatkan rasa aman dan bebes dari segala bentuk kekerasan sesuai dengan falsafah Pancasila dan Undang-undang Republik Indonesia tahun 1945. b. Bahwa segala bentuk kekerasan, terutama Kekerasan dalam rumah tangga merupakan pelanggaran hak asasi manusia, dan kejahatan terhadap martabat kemanusiaan serta bentuk deskriminasi yang harus dihapus. c. Bahwa korban kekerasan dalam rumah tangga yang kebanyakan adalah perempuan, hal itu harus mendapatkan perlindungan dari Negara dan/atau masyarakat agar terhindar dan terbebas dari kekerasan atau ancaman kekerasan, penyiksaan, atau perlakuan yang merendahkan derajat dan martabat kemanusiaan. d. Bahwa berdasarkan pertimbangan sebagai dimaksud dalam huruf a, huruf $b$, huruf $c$, dan huruf d perlu dibentuk Undang-undang tentang penghapusan kekerasan dalam rumah tangga.

Tindak kekerasan yang dilakukan suami terhadap isteri sebenarnya merupakan unsur yang berat dalam tindak pidana, dasar hukumnya adalah KUHP (kitab undangundang hukum pidana) pasal 356 yang secara garis besar isi pasal yang berbunyi: "Barang siapa yang melakukan penganiayaan terhadap ayah, ibu, isteri atau anak diancam hukuman pidana".

Sudah waktunya pemerintah bersama-sama masyarakat mencanangkan Zero tolerance terhadap kekerasan. Artinya tidak ada toleransi sekecil apapun terhadap tindakan kekerasan terhadap perempuan, baik dalam keluarga, masyarakat, dan negara. Kebijakan ini sebagai bagian dari penghapusan segala bentuk diskriminasi terhadap perempuan. Hal ini sejalan dengan PBB (united Nations) yang telah membentuk Komisi Kedudukan Perempuan (Commission on the Status of Women) yang bertugas menentukan langkahlangkah, kebijakan, serta memantau tindakan PBB bagi kepentingan perempuan. Hal ini dilakukan karena PBB melihat bahwa diskriminasi terhadap perempuan tetap berlangsung di banyak 


\section{JURNAL ABDIMAS

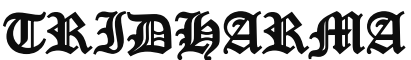

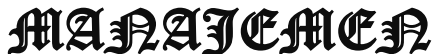

P-ISSN 2615-6849, E-ISSN 2622-3686

Jurnal ABDIMAS Vol. 1,No. 3,September 2020,Hal (42-47)

@ Prodi Manajemen Fakultas Ekonomi Universitas Pamulang

Email: abdimasjurnal.unpam@ gmail.com Telp: (021) 741-2566 negara sehingga perlu dikeluarkannya sebuah Deklarasi Penghapusan Diskriminasi Terhadap Perempuan.

\section{Perlindungan Anak}

Keberadaan Undang-Undang Nomor 35 Tahun 2014 tentang Perubahan Atas Undang-Undang Nomor 23 Tahun 2002 tentang Perlindungan Anak, mempertegas perlunya pemberatan sanksi pidana dan denda bagi pelaku kejahatan terhadap anak terutama kepada kejahatan seksual yang bertujuan untuk memberikan efek jera, serta mendorong adanya langkah konkrit untuk memulihkan kembali fisik, psikis dan sosial anak.

Hal tersebut perlu dilakukan untuk mengantisipasi anak (korban kejahatan) dikemudian hari tidak menjadi pelaku kejahatan yang sama. Karena berdasarkan fakta yang terungkap pada saat pelaku kejahatan terhadap anak (terutama pelaku kejahatan seksual) diperiksa di persidangan, pada kenyataannya ada beberapa pelaku yang mengaku bahwa pernah mengalami tindakan pelecehan seksual ketika pelaku masih berusia anak.

Oleh karenanya, keberadaan undangundang ini semoga menjadi harapan baru dalam melakukan perlindungan terhadap anak. Berikut adalah beberapa poin penting dalam undnag-undang tersebut.

Pasal 1 Dalam Undang-Undang ini yang dimaksud dengan: 1. Anak adalah seseorang yang belum berusia 18 (delapan belas) tahun, termasuk anak yang masih dalam kandungan. 2. Perlindungan Anak adalah segala kegiatan untuk menjamin dan melindungi Anak dan hak-haknya agar dapat hidup, tumbuh, berkembang, dan berpartisipasi secara optimal sesuai dengan harkat dan martabat kemanusiaan, serta mendapat perlindungan dari kekerasan dan diskriminasi.
Pasal 76E UU Setiap Orang dilarang melakukan Kekerasan atau ancaman Kekerasan, memaksa, melakukan tipu muslihat, melakukan serangkaian kebohongan, atau membujuk Anak untuk melakukan atau membiarkan dilakukan perbuatan cabul.

Pasal 82 (1) Setiap orang yang melanggar ketentuan sebagaimana dimaksud dalam Pasal 76E dipidana dengan pidana penjara paling singkat 5 (lima) tahun dan paling lama 15 (lima belas) tahun dan denda paling banyak Rp5.000.000.000,00 (lima miliar rupiah). (2) Dalam hal tindak pidana sebagaimana dimaksud pada ayat (1) dilakukan oleh Orang Tua, Wali, pengasuh Anak, pendidik, atau tenaga kependidikan, maka pidananya ditambah $1 / 3$ (sepertiga) dari ancaman pidana sebagaimana dimaksud pada ayat (1).

\section{METODE PELAKSANAAN}

Metode pelaksanaan pengabdian ini dilakukan dalam beberapa kegiatan yaitu tahap survei yaitu sosialisasi dilakukan dengan menyusun berbagai hal yang akan disampaikan pada saat kegiatan pengabdian yang akan dilakukan yang meliputi: penyusunan materi yang akan diberikan, penyusunan jadwal pemberian materi, pembagian tugas tim pengabdian dan survei ke lokasi pengabdian. Tahap sosialisasi yaitu sebelum kegiatan pengabdian dilaksanakan terlebih dahulu dilakukan tahap sosialisasi yaitu melakukan silaturahmi dengan jajaran kelurahan, menyampaikan maksud dan tujuan pengabdian ini. Pada tahap ini juga dilakukan jalinan kerjasama dan menentukan jadwal kegiatan pengabdian. Tim pelaksana kegiatan pengabdian pada masyarakat adalah dosen Magister Hukum UNPAM. Metode kegiatan yang digunakan adalah sosialisasi menggunakan aplikasi zoom karena adanya aturan PSBB dari Pemerintah Kota Tangerang Selatan. 


\section{JURNAL ABDIMAS

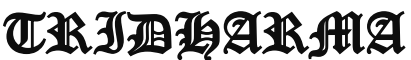

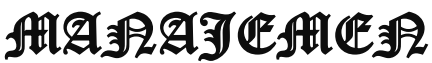

P-ISSN 2615-6849, E-ISSN 2622-3686

Jurnal ABDIMAS Vol. 1,No. 3,September 2020,Hal (42-47)

@Prodi Manajemen Fakultas Ekonomi Universitas Pamulang

Email: abdimasjurnal.unpam@gmail.com Telp: (021) 741-2566

\section{HASIL DAN PEMBAHASAN}

Pengabdian Masyarakat Universitas Pamulang yang dilakukan oleh dosendosen Magister Hukum UNPAM menggunakan aplikasi zoom telah berjalan dengan lancar dan mendapat sambutan hangat dari tempat pelaksanaan kegiatan ini yaitu di di Tangerang Selatan tepatnya di Rukun Warga (RW) 017, Kelurahan Pamulang Barat, Kecamatan Pamulang.

Metode yang digunakan pada Pengabdian Kepada Masyarakat ini berupa penympaian secara virtual karena adanya Pandemi Covid-19 dan diterapkannya Pembatasan Sosial Berskala Besar (PSBB). Pelaksanaan melalui aplikasi zoom. Kegiatan ini menetapkan target audiens adalah pengurus RT, RW.

Adapun jadwal dan tempat pelaksanaan kegiataan sebagai berikut: Hari/Tanggal : Rabu 10 Juni 2020 s/d 12 April 2020, Waktu : 09.00 s/d Selesai, Tempat : Aplikasi Zoom

Harapan kami dengan pengabdian ini dapat membuka wawasan masyarakat yang diperoleh adalah bertambahnya keilmuan bagi para Masyarakat tentang pengeloaan KDRT dan Perlindungan anak.

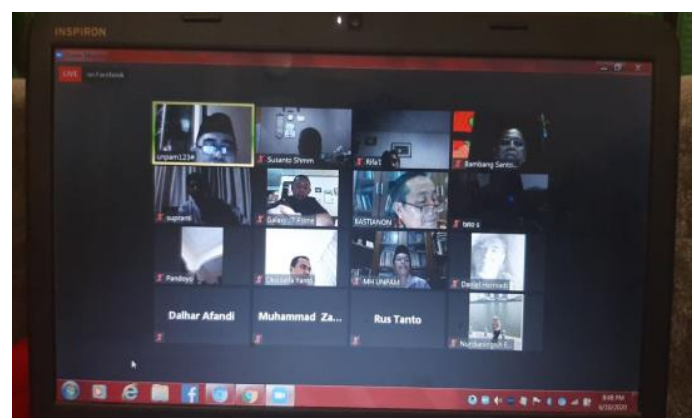

Gambar 1 : Melalui Aplikasi Zoom Team PKM sedang meberikan Materi

\section{KESIMPULAN DAN SARAN}

Kesimpulan
Peserta memahami mengenai jenis-jenis KDRT, hak atas anak serta perlindungn hukum atas anak.

\section{Saran}

Pengabdian lanjutan diharapkan bisa dilakukan secara offline.

\section{DAFTAR PUSTAKA}

Darusman, Y. M., Susanto, S., Anggraeni, R. D., Gueci, R. S., \& Yanto, O. (2019). Penyuluhan Peraturan Perundang-Undangan Pemilihan Umum (PEMILU) Tahun 2019 (Studi Kasus pada Politeknik Ilmu Pemasyarakatan (POLTEKIP) Kementerian Hukum dan HAM RI, Depok, Jawa Barat). Jurnal Abdi Masyarakat Humanis, 1(1).

Darusman, Y. M., Susanto, S., Anggraeni, R. D., Bachtiar, B., \& Bastinaon, B. (2020). SOSIALISASI UNDANG-UNDANG PERLINDUNGAN ANAK DAN KDRT KELURAHAN PULAU PANGGANG KABUPATEN KEPULAUAN SERIBU. JURNAL LOKABMAS KREATIF, 1(1), 76-82.

Iqbal, M. I., Susanto, S., \& Sutoro, M. (2019). Functionalization of ECourt System in Eradicating Judicial Corruption at The Level of Administrative Management. Jurnal Dinamika Hukum, 19(2), 370-388.

Lesmana, R., Sunardi, N., Hasbiyah, W., Tumanggor, M., \& Susanto, S. (2019). Manajemen Alokasi Dana Desa dalam Upaya dan Strategi Mewujudkan Desa Sejahtera Mandiri di Desa Cihambulu, Kec. Pabuaran, Kab. Subang, Jawa Barat. Jurnal Abdi Masyarakat Humanis, 1(1).

Pasaribu, V. L. D., Agrasadya, A., 
JURNAL ABDIMAS

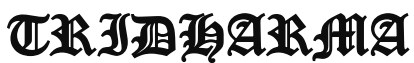

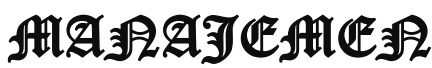

P-ISSN 2615-6849, E-ISSN 2622-3686

Jurnal ABDIMAS Vol. 1,No. 3,September 2020,Hal (42-47)

@ Prodi Manajemen Fakultas Ekonomi Universitas Pamulang

Email: abdimasjurnal.unpam@gmail.com Telp: (021) 741-2566
Shabrina, N., \& Krisnaldy, K. (2020). MENJADI ENTERPRENEUR MUDA YANG MEMILIKI JIWA LEADERSHIP UNTUK MENGHADAPI MASA

DEPAN. Abdi Laksana, 1(1).

Sahroni, S., Susanto, S., Sutoro, M., Mukrodi, M., \& Apriansyah, M. (2020). PENUMBUHAN WIRAUSAHA BARU PADA MAJELIS DA'WAH AL'ADNI. Abdi Laksana, 1(2).

Susanto, S., \& Iqbal, M. (2019). Pengabdian Kepada Masyarakat Dalam Sinergitas Akademisi Dan TNI Bersama Tangkal Hoax Dan Black Campaign. CARADDE: Jurnal Pengabdian Kepada Masyarakat, 2(1), 8-16.

Susanto, S., Iqbal, M., \& Supriyatna, W. (2020). IMPLEMENTASI ECOURT PADA PENDAFTARAN GUGATAN DAN PERMOHONAN DI PENGADILAN AGAMA TIGARAKSA DALAM RANGKA MEWUJUDKAN PERADILAN CEPAT, SEDERHANA DAN BIAYA RINGAN DENGAN DIDUKUNG

TEKNOLOGI. PROCEEDINGS HUMANIS UNIVERSITAS PAMULANG, 1(1).

Yanto, O., Susanto, S., Darusman, Y. M., Wiyono, B., \& Gueci, R. S. (2020). SOSIALISASI DAN PELATIHAN E-LITIGASI DI LEMBAGA BANTUAN HUKUM UNGGUL TANGERANG SELATAN GUNA MENINGKATKAN

$\begin{array}{lr}\text { PROFESINALISME } & \text { DALAM } \\ \text { RANGKA PENDAMPINGAN } \\ \text { MASYARAKAT } & \text { PENCARI } \\ \text { KEADILAN } & \text { MELALUI } \\ \text { APLIKASI KOMPUTER. Jurnal } \\ \text { ABDIMAS Tri } & \text { Dharma } \\ \text { Manajemen, 1(2). }\end{array}$

Yanto, O., Susanto, S., Nugroho, A., Santoso, B., \& Gueci, R. S. (2020). SOSIALISASI KEKAYAAN INTELEKTUAL GUNA

MENUMBUHKEMBANGKAN USAHA DALAM RANGKA MENGHADAPI PERSAINGAN GLOBAL PADA REVOLUSI 4.0. Abdi Laksana, 1(2). 